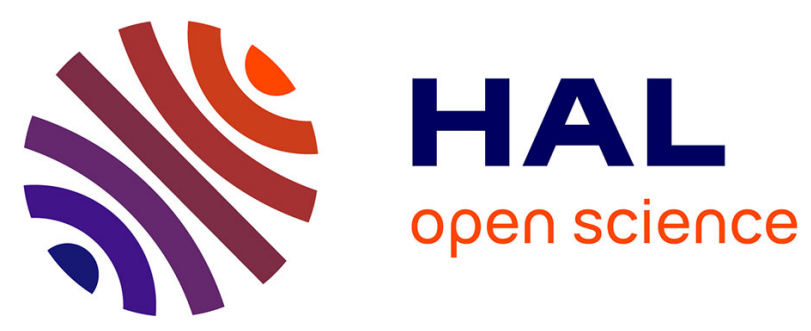

\title{
Methodology of porosity modeling for friction pad: Consequence on squeal
}

\author{
Vincent Magnier, Emmanuel Roubin, Jean-Baptiste Colliat, Philippe \\ Dufrenoy
}

\section{- To cite this version:}

Vincent Magnier, Emmanuel Roubin, Jean-Baptiste Colliat, Philippe Dufrenoy. Methodology of porosity modeling for friction pad: Consequence on squeal. Tribology International, 2017, 109 (78-85), 10.1016/j.triboint.2016.12.026 . hal-01450382

\section{HAL Id: hal-01450382 \\ https://hal.science/hal-01450382}

Submitted on 21 Dec 2018

HAL is a multi-disciplinary open access archive for the deposit and dissemination of scientific research documents, whether they are published or not. The documents may come from teaching and research institutions in France or abroad, or from public or private research centers.
L'archive ouverte pluridisciplinaire HAL, est destinée au dépôt et à la diffusion de documents scientifiques de niveau recherche, publiés ou non, émanant des établissements d'enseignement et de recherche français ou étrangers, des laboratoires publics ou privés. 


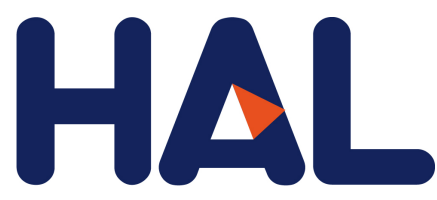

archives-ouvertes

\title{
Methodology of porosity modeling for friction pad: Consequence on the squeal instability
}

\author{
V. Magnier, E. Roubin, J.B. Colliat, P. Dufrénoy
}

\section{To cite this version:}

V. Magnier, E. Roubin, J.B. Colliat, P. Dufrénoy. Methodology of porosity modeling for friction pad: Consequence on the squeal instability. Tribology International, Elsevier, 2017, 109, pp.78 - 85. $<10.1016 /$ j.triboint.2016.12.026>. <hal-01737147>

\section{HAL Id: hal-01737147 \\ https://hal.archives-ouvertes.fr/hal-01737147}

Submitted on 19 Mar 2018

HAL is a multi-disciplinary open access archive for the deposit and dissemination of scientific research documents, whether they are published or not. The documents may come from teaching and research institutions in France or abroad, or from public or private research centers.
L'archive ouverte pluridisciplinaire HAL, est destinée au dépôt et à la diffusion de documents scientifiques de niveau recherche, publiés ou non, émanant des établissements d'enseignement et de recherche français ou étrangers, des laboratoires publics ou privés. 


\title{
Methodology of porosity modeling for friction pad: Consequence on the squeal instability
}

\author{
V. Magnier ${ }^{123 *}$, E. Roubin ${ }^{4}$, J.B. Colliat ${ }^{123}$, P. Dufrénoy ${ }^{123}$ \\ ${ }^{1}$ Université Lille Nord de France, F-59000 Lille, France \\ ${ }^{2}$ Lille1-LML, F-59655 Villeneuve d'Ascq, France \\ ${ }^{3}$ CNRS, UMR 8107, F-59655 Villeneuve d'Ascq, France \\ ${ }^{4}$ Grenoble-3SR, UMR 5521, F-38610 Giéres, France
}

\begin{abstract}
Mechanical property is an important parameter of friction material as it influences contact distribution (tribological and thermo-mechanical behavior), dynamic behavior (and then squeal propensity). Due to the process, the percentage of porosity in the volume is near $10 \%$. So, a friction pad has been characterized by a topographical study using X-ray. This step permits to obtain some information concerning the porosity. In a second step, a simplified pin-on-disc is modeled using finite element method considering initially homogenized friction material and secondly heterogeneous friction material including the pores. The pore distributions are generated using a representative random fields technique. The introduction of pores shows clearly some differences on dynamical behavior between homogenized and heterogeneous materials consideration.
\end{abstract}

Keywords: Squeal, Morphological modeling, Finite Element Analysis, Heterogeneous material.

\section{Introduction}

A brake system can generate noise emissions. This noise can be classified into different categories based on the frequencies and excitation sources that

* Corresponding author. Tel: +33 (0)3 287673 57; fax: +33 (0)3 28767361 E-mail address: vincent.magnier@polytech-lille.fr 
occur like judder, groan, moan, howl and squeal [2]. The latter remains a major 5 concern of the transportation industry in spite of much research and development work performed over the last few decades. Squeal is characterized by high frequencies ranging from 1 to $10 \mathrm{kHz}$ associated with a high sound pressure level up to $120 \mathrm{~dB}$ [2]. Several general and global theoretical models have been developed to understand the acoustic emission mechanisms of sliding systems. Some mechanisms lead to vibrations, like flutter instabilities 15], while others sustain vibration, e.g., producing a limit cycle, like stick-slip [16] and sprag-slip 23]. Flutter instability, in a case without damping and gyroscopic forces is the coalescence of two eigenfrequencies, called mode lock-in. The instability is associated with a non null real part of the eigenvalues that are complex due to 15 the asymmetry of the matrix stiffness due to contact terms in the modal analysis. Consequently, mode lock-in implies instabilities in systems and can lead to vibrations in the brake system and noise generation [17] [11].

From a numerical point of view, brake models are mostly carried out with homogeneous and mostly isotropic materials. In the literature, minimal models or models based on the real geometry using finite element method are found to gain understanding of the role of macroscopic parameters like coefficient of friction, mechanical properties, etc. [12], 13], 86], 25] etc. Recently, some studies have been performed by introducing heterogeneities in friction pad like [3] 24] [14] 7] 4] where the heterogeneities of friction pad are considered as homogeneous material using homogenization technique. In [18], a heat transfer analysis of the brake pads with porous materials is performed using mathematical homogenization. To date, most modeling practices consider heterogeneity qualitatively and their choice of input parameters is subjective. Recently, some work [1] has found some applications of a mixture of geometry, topology, probability, and so statistics data to many problems.

But it is well known that the lining materials of automotive brakes are usually composites formed by compaction of coarse powders including many different components (typically 20 to 30 ). The development of friction materials is mainly based on an experimental approach with empirical trial-error methods. 
But in nowadays context, this way is long and expensive especially with the norms (environmental, safety etc.) becoming more and more restrictive. The mechanical properties of the components span over a wide range, from very soft and easily worn phenolic resins to hard and wear resistant fibers and abrasive particles. Types and relative amounts of ingredients have been determined

40 by empirical observations including binder resin, reinforcing fibers, solid lubricants, abrasives, fillers and friction modifiers. In [5], typical brake materials are reviewed and their advantages and disadvantages in contemporary brake applications are discussed. In addition to the basic brake components, some porosity ( 5 to $10 \%$ or more) is normally present from the process. Pores seem

45 to be important to control the tribological and mechanical characteristics as well as other ingredients contained in a brake lining. However the actual effect of the porosity is empirical and not really known specifically its influence on vibration induced by friction and squeal. To consider the description of a porous solid, the principal methods found in the literature are stereology, radi50 ation scattering, pycnometry, adsorption, intrusion, suction, maximum bubble pressure, fluid flow, immersion or adsorption calorimetry, thermoporometry, size exclusion chromatography, Xenon NMR and ultrasonic methods as mentioned by [21]. For brake pads, some studies have been performed to determine the porous network volume quantification using mercury porosity [20]. However,

55 this method is insufficient to analyze, to understand and to develop other characteristics like shape ones, number of pores etc. On the other hand, X-ray makes possible to observe and to analyze the characteristics of pores such as shape, distribution and the positional relation to other materials in the lining. [10] Kimura et al. analyze the brake lining pores and propose an improvement for ${ }_{60}$ more accurate data by a higher contrast resolution image using gallium.

The aim of this paper is to consider explicitly heterogeneity of friction material induced by the porosity on dynamic instabilities. A methodology is proposed starting from a characterization of heterogeneities of a friction pad. The mi65 crostructure description is provided by X-ray microtomography. For this study, 
a reduced formulation friction pad with six components has been chosen. In a second step, a morphological modeling framework for the pores generation using information found in the tomography study is described. This heterogeneous description allows including the porosity in a pin-on-disc model which is per-

70 formed to identify mode coupling with a complex eigenvalues analysis. Due to the random distribution of pores, some draw of pores dispersal are performed to have a tendency on the dynamical behavior results.

\section{Formulation of friction pad}

A typical brake pad material contains quite a number of components, usually

7520 to 30. The pad lining materials are categorized as metallic, semi-metallic, organic and carbon-based, depending on their composition. The components are classified into four broad groups: binders, reinforcing fibers, fillers, and frictional additives/modifiers, based on the major function they perform apart from controlling friction and wear performances. The binder hold the ingredients together, to maintain structural integrity of the brake lining under varying mechanical and thermal loading. The structural components provide the mechanical reinforcement of the composite matrix; fillers make up the volume of the brake lining, while keeping the cost down; friction modifiers stabilize the coefficient of friction and wear rate. Apart from these basic considerations, these components perform synergistically in controlling friction and wear performances of the brake pad. Most studies on squeal use standard friction material primarily issued from the automotive industry. It is not rare to find in a commercial friction between 20 and 30 components. This kind of formulation makes difficult a fine analysis of dynamic behavior. For this study, a reduced

90 formulation friction pad has been developed. Here, friction pad contains only six components (see Table 1). This material is developed in collaboration with the company FLERTEX.

For the process, all constituents are firstly accurately weighed and added into mixer. Then, the mixture is loaded into a mold. The molded pad samples 
are hot pressed $\left(160^{\circ} \mathrm{C}\right)$. The pressure of the press is released several times to let go of the gases generated during the cross linking reaction of the phenolic resin. The brake samples are subsequently post cured. Figure 1 shows the different

\begin{tabular}{|c|c|}
\hline Component & Category \\
\hline \hline Resin & Matrix \\
\hline Baryte & Binder \\
\hline Twaron fibers & Structural materials \\
\hline Steel fibers & Abrasive materials \\
\hline Mineral fibers & Structural and abrasive materials \\
\hline Graphite & Lubricant \\
\hline
\end{tabular}

Table 1: Formulation of the simplified friction pad

components introduced before the process.

Another phase appears during the process step: the porosity arises mainly during the degassing step.

\section{Characterization of heterogeneities in friction pad}

To characterize the friction pad, a cylindrical sample has been extracted from a friction pad along the thickness. This sample has a diameter of $10 \mathrm{~mm}$ and a height of $14 \mathrm{~mm}$. Thereafter, this sample has been submitted to a morphology analysis using X-rays. With this technique, the interactions with matter permit to have information about the composition of the sample, and particularly the porosity. Due to the density of components and the high atom number of the binder (baryte), it is necessary to have a powerful energy to pass through the material. This step has been performed at European Synchrotron Radiation Facility. Figure 2(a) shows a typical slice in gray level (from 0 to 255) obtained from the X-rays study. A stack of one thousand pictures following a part of the height of the sample has been obtained. Each picture has a resolution of $2000 * 2000$ pixels. So, the voxel dimension is fixed to $5 * 5 * 5 \mu m^{3}$ leading to 


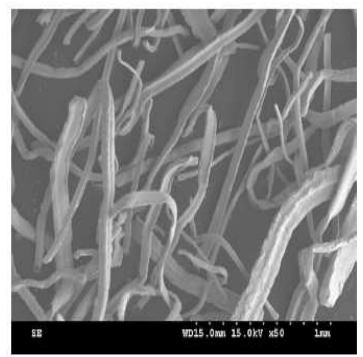

(a)

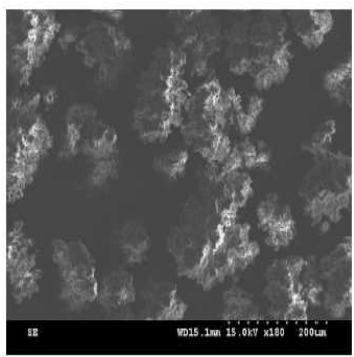

(d)

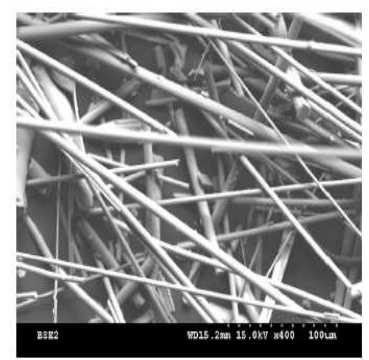

(b)

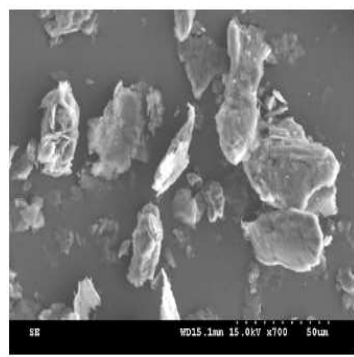

(e)

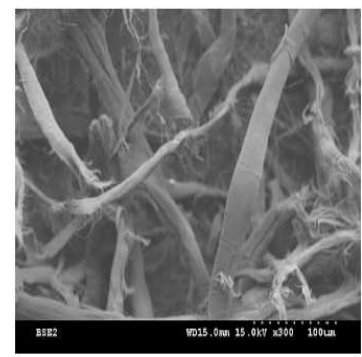

(c)

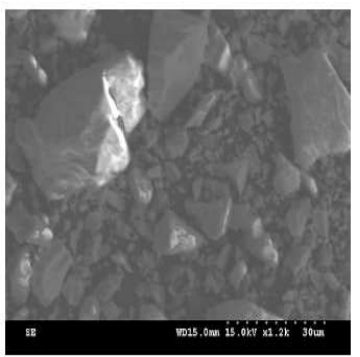

(f)

Figure 1: SEM of different components: (a) Steel fibers, (b) Mineral fibers, (c) Twaron fibers, (d) Resin, (e) Natural graphite, (f) Barite

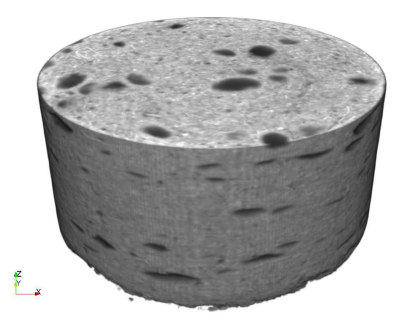

(a)

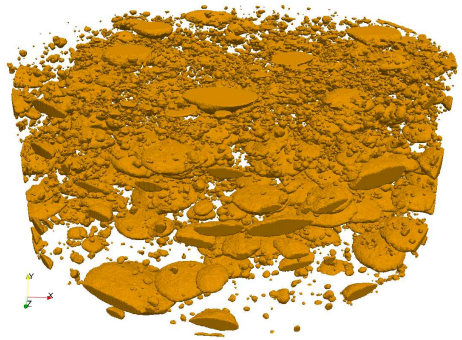

(b)

Figure 2: Tomography image to 3D reconstitution of porosity: (a) Tomography image, (b) Reconstitution in 3D

have a high definition of each component in the sample (porosity, fibers, resin, 115 graphite and baryte).

The result of the X-ray tomography is illustrated in figure 2(a) with a height 
viewport fixed to $4 \mathrm{~mm}$ where the porosity seems to be important at the mesoscale. To highlight this feeling, a segmentation of each pictures using two colors is performed using the free software ImageJ [22]. A 3D rendering of pore distribution 120 is described in figure $2(\mathrm{~b})$

Firstly in the complete sample, in terms of characterization information, the number of pores is close to 17000 with size which varies from some microns to millimeters. The volume fraction obtained for this sample is close to $10 \%$. Secondly, it is interesting to see that the morphological aspect of porosity is close to a flattened spheroid, with the main axis perpendicular to the pad thickness direction. Figure 3(a) (resp. 3(b) shows the pore shape for clipping plans in ydirection (resp. z-direction). This special shape is essentially due to the process procedure where a uniaxial pressure on the top of the pad is applied.

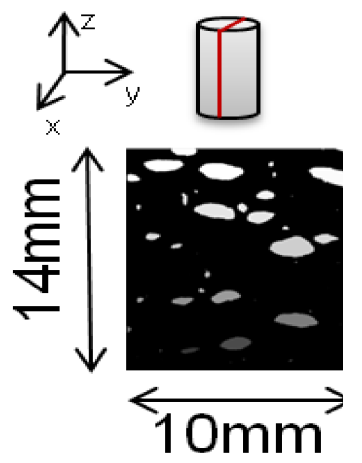

(a)

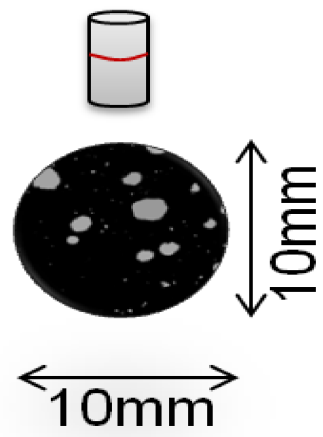

(b)

Figure 3: Tomography images illustrating pore shape: (a) Clipping plan $y=0$, (b) Clipping plan $\mathrm{z}=10 \mathrm{~mm}$

In view of this result, it is necessary to model the porosity which seems to be of the first order on the mechanical behavior. Indeed, the understanding of the impact of this heterogeneity should permit to improve the process without changing the formulation. Here, the target performance will be the dynamic behavior. 


\section{Morphological modeling of pores}

In this section, a short presentation of a morphological modeling framework for the pores generation is described. The complete approach is described in [19]. Indeed, the porosities information described before is characterized for the sample where the shape and dimensions are fixed. So, a tool to generate a pores distribution for all shapes of the friction pad keeping information found in the tomography study must be developed.

The framework deals with correlated Random Fields (RF), which are random spatial continuous functions. By thresholding such a function, one obtains a so-called excursion that is a binary morphology of random shape. This shape clearly relies on the properties of the chosen RF, as well as on the value of the threshold. Several recent results [1] coming from the geometry of RF create a mathematical and theoretical link between this excursion shape and the RF characteristics, giving the possibility of controlling the excursion as morphological model and to match the morphology extracted from X-ray tomography. From a numerical point of view, several methods have been developed to simulate correlated RF. Here the Turning-band method is chosen, which transforms a 3D simulation into a 1D case. An analytic formula links the random field characteristics with geometrical and topological quantities (volume, surface area, Euler characteristic...) of the underlying excursion set. The last set of parameters is extracted from tomography description performed before.

155 For a realistic modeling of a concrete like material, both in terms of geometrical and topological quantities, due to the Gaussian case limitation, an application of the random field is made.

To illustrate the approach, let be a realization $\gamma$ defined as above in figure 4 and $u$ (dashed red line in figure 4(a) a chosen threshold. $\gamma$ (blue curve in figure 4(a) is a Gaussian function randomly generated where mean, variance and correlation length are determined. The underlying excursion set $A_{u}$ is defined by the points of $M$ where the values are above a value $u$. This principle, applied for 2 dimensions, is shown in figure 4(b) In order to provide a global description of 


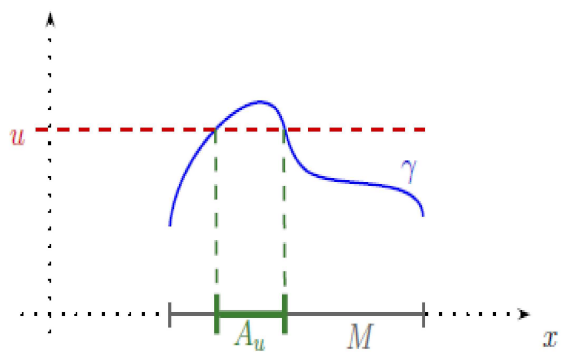

(a)
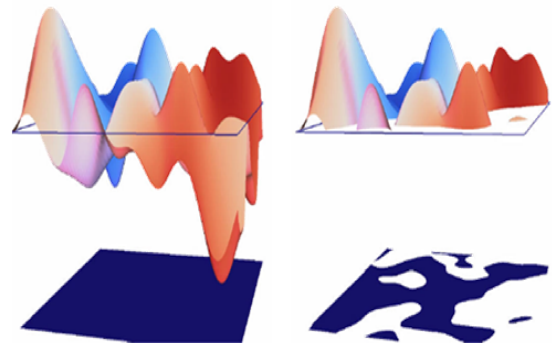

(b)

Figure 4: Illustration of the thresholding technique in 1D and 2D cases.: (a) Thresholding technique in 1D case, (b) Thresholding technique in 2D case

the resulting morphology, the Lipschitz-Killing Curvatures, hereafter LKCs, are chosen. The LKC are somehow "measures" sizes of a set $A_{u}$ at N-dimensions. In a $\mathrm{N}$-dimensional space $\mathrm{N}+1$ LKCs can be defined where each can be thought of measures of the "j-dimensional sizes" of $A_{u}$. In our three-dimensional case, the four LKCs, denoted by $\mathcal{L}_{j}, \mathrm{j}=0 . .3$, provide both geometrical - $\mathcal{L}_{1}, \mathcal{L}_{2}, \mathcal{L}_{3}$ and topological $-\mathcal{L}_{0}$ - descriptions of the morphology $A_{u}$. They are defined by:

- $\mathcal{L}_{3}\left(A_{u}\right)$ : the three dimensional volume of $A_{u}$.

- $\mathcal{L}_{2}\left(A_{u}\right)$ : half the surface area of $A_{u}$.

- $\mathcal{L}_{1}\left(A_{u}\right)$ : twice the caliper diameter of $A_{u}$.

- $\mathcal{L}_{0}\left(A_{u}\right)$ : the Euler characteristic of $A_{u}$, which contrary to the other LKCs is a topological measure.

For example, the Euler characteristic $\left(\mathcal{L}_{0}\right)$ for a ball or a cube is fixed to 1 but differs from a hollow ball $\left(\mathcal{L}_{0}=2\right)$ or a ring torus $\left(\mathcal{L}_{0}=0\right)$. These $\mathcal{L}_{j}$ are specified from tomography data.

The chosen shape friction pad is a parallelepiped of $20^{*} 20^{*} 10 \mathrm{~mm}^{3}$. An example of pores generation (grey parts) is illustrated in figure 5 with $\mathcal{L}_{3}\left(A_{u}\right)=10 \%$, $\mathcal{L}_{2}\left(A_{u}\right)=1.8, \mathcal{L}_{1}\left(A_{u}\right)=1.5$ and $\mathcal{L}_{0}\left(A_{u}\right)=17000$. 


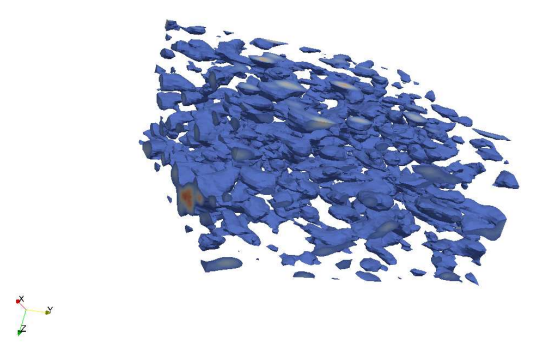

Figure 5: Generation of porosity in a parallelepiped friction-pad using tomography data extracted from an elementary cylinder.

\section{Introduction of pores in finite element analysis}

In this section, the finite element model is described. The geometry is inspired by an experimental set-up developed at the Laboratoire de Mécanique de Lille and described further in figure 6(a), This experimental set-up is dedicated to squeal noise study and is focused on the role of friction material by simplifying its dynamic behavior with a reduced number of components. The sensitivity to material formulation and geometry on squeal occurrence has been evidenced by [6]. However the impact of porosity is experimentally very difficult to determine and modeling is required.

\subsection{Homogenization}

In this part, the homogenized elastic properties for friction pad included porosity is performed. From now, only pores of more than one hundred micrometers are taken into account due to the limit of the meshing process and CPU time consideration. Indeed, here the pores are explicitly meshed requiring very fine elements ( $\sim 10 \mu \mathrm{m}$ for mesh size near the pores). The volume fraction of porosity considering with this size and obtained with this fixed sample is $9.6 \%$. The average strains are introduced as degrees of freedom of Reference Points and Homtools [Homtools] automatically generates the linear constraints between these additional degrees of freedom and the displacements on the boundary of 
the RVE. Thanks to duality properties, the reaction forces at the Reference Points are the average stresses multiplied by the volume of the RVE. With this method, prescribing average strains or stresses become as easy as prescribing displacements or concentrated forces at a node. Here, the kinematic uniform boundary conditions are used. This can be expressed by the displacement $u$ which is imposed at point $x$ belonging to the boundary $\partial V$ such that:

$$
u_{i}=E_{i j} x_{j} \quad \forall x \in \partial V
$$

$E_{i j}$ are the Cartesian components of a given symmetrical second-rank tensor that does not depend on $x$. This implies that the mean strain over $\mathrm{V}$ is:

$$
\left\langle\varepsilon_{i j}\right\rangle=\frac{1}{V} \int_{V} \varepsilon_{i j} d V=E_{i j}
$$

Homogenized test has been performed with one hundred random porosity distributions. The mechanical property of matrix is fixed to $3000 \mathrm{MPa}$ for Young modulus and 0.3 for Poisson coefficient. For the result, the average of homogenized compressive modulus obtained is $2680 \mathrm{MPa}$ with a difference between the minimal and maximal equal to $134 \mathrm{MPa}$ as shown in table 2 .

\begin{tabular}{|c|c|c|c|}
\hline Average & Standard deviation & Minimum & Maximum \\
\hline $2680 \mathrm{MPa}$ & $39 \mathrm{MPa}$ & $2596 \mathrm{MPa}$ & $2730 \mathrm{MPa}$ \\
\hline
\end{tabular}

Table 2: Homogenized compressive modulus of the material considering porosity

\subsection{Description of the pin-on-disc model}

The test bench is made of a rigid stand, a thin plate, a pad-housing, a friction pad and a disc as shown in figure 6(a), The friction pad is glued to a pad housing and the latter one is tied with a thin plate. The thin plate extremities are embedded with a rigid block which permits to pilot the displacement.

This experimental set-up allows a translation of the pad but also tilting with the flexibility of the thin plate. This experimental set-up has been modeled by the finite element method to obtain the eigenfrequencies of the system. They are 


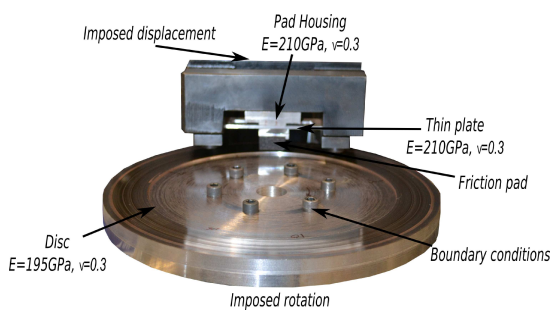

(a)

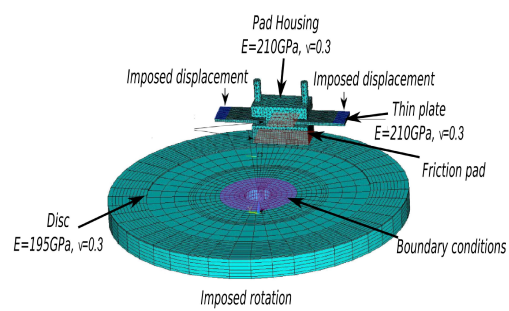

(b)

Figure 6: Experimental set-up and the associated finite element model + Boundaries conditions: (a) Experimental set-up, (b) Finite element model

obtained into two steps. Firstly, a static equilibrium under pressure and sliding conditions is performed in order to obtain the contact pressure distribution which is injected in a second step of the computation. This second step consists in a complex eigenfrequencies analysis in order to determine the frequencies of the system after performing a linearization at the steady sliding state from the first step. The used contact algorithm is the penalty method with a contact stiffness fixed to $10^{14} \mathrm{~N} / \mathrm{m}$.

The pad-housing and the thin plate are made of steel with a Young's modulus of $210000 \mathrm{MPa}$ and a Poisson ratio of 0.3. No damping is taken into account in this paper. The dimensions of the pad are fixed to $20 * 20 * 10 \mathrm{~mm}^{3}$. The thickness of the thin plate is fixed to $2 \mathrm{~mm}$. The extremities of the thin plate are submitted to a vertical displacement of $-0.3 \mathrm{~mm}$ leading to a normal force of 300 N. To illustrate the strategy of study, the analysis has been firstly carried out with a homogenized and an isotropic friction-pad material.

\subsection{Dynamic analysis of homogenized case and heterogeneous case without con-} tact

In this section, an eigenvalue analysis is performed on the pin-on-disc previously described without contact between pad and disc. First, a homogenized friction-pad is considered with a value of $2680 \mathrm{MPa}$ for the Young's modulus which is the average value of the material with porosities previously obtained. 
The results of the eigenfrequencies associated to eigenmodes are summarized in table 3. Here, only the first three pad eigenmodes are presented in view of their contribution in the configuration performed in section 5.5 .

A modal assurance criterion on the pad modes is performed between homogenized and heterogeneous cases and shows a quasi-similarity between modes.

\begin{tabular}{|c|c|c|c|}
\hline Eigenmodes & $\begin{array}{c}\text { Eigenfrequencies } \\
\text { for the } \\
\text { homogenized case }\end{array}$ & $\begin{array}{c}\text { Eigenfrequencies } \\
\text { for one } \\
\text { heterogeneous case }\end{array}$ & Relative error \\
\hline & $793 \mathrm{~Hz}$ & $770 \mathrm{~Hz}$ & $2.9 \%$ \\
\hline & $1090 \mathrm{~Hz}$ & $1047 \mathrm{~Hz}$ & $3.9 \%$ \\
\hline
\end{tabular}

Table 3: Eigenfrequencies for homogenized and heterogeneous cases without contact between pad and disc

The relative error (table 3) shows a quasi-similarity of the eigenfrequencies values between heterogeneous and homogenized friction pad. However, the eigenfrequencies values obtained with the heterogeneous cases are always 
smaller than the ones obtained with the homogenized case, this tendency can be explained by the difference of the mesh size localized at the friction material. Indeed, the mesh is the same between the different cases except on the friction pad material where the element size is equal to $\sim 200 \mu \mathrm{m}$ (resp. $\sim 10 \mu \mathrm{m}$ ) for homogeneous (resp. heterogeneous) case.

\subsection{Results with friction pad homogenized material with contact}

For this simulation, a homogenized friction-pad is considered with a value of $2680 \mathrm{MPa}$ for the Young's modulus which is the average value of the material with porosities previously obtained. The complex eigenvalues analysis of the complete system has been performed with a variation of the coefficient of friction from 0.1 to 0.8 . The complex eigenvalue analysis provides the tool to trace the regions of the parameter space that leads to an instability of the system. Figure 7 shows the complex eigenvalues of the system function of the coefficient of friction. The solid lines represent the complex part i.e. the frequencies while the dashed line represents the maximum real part of the system.

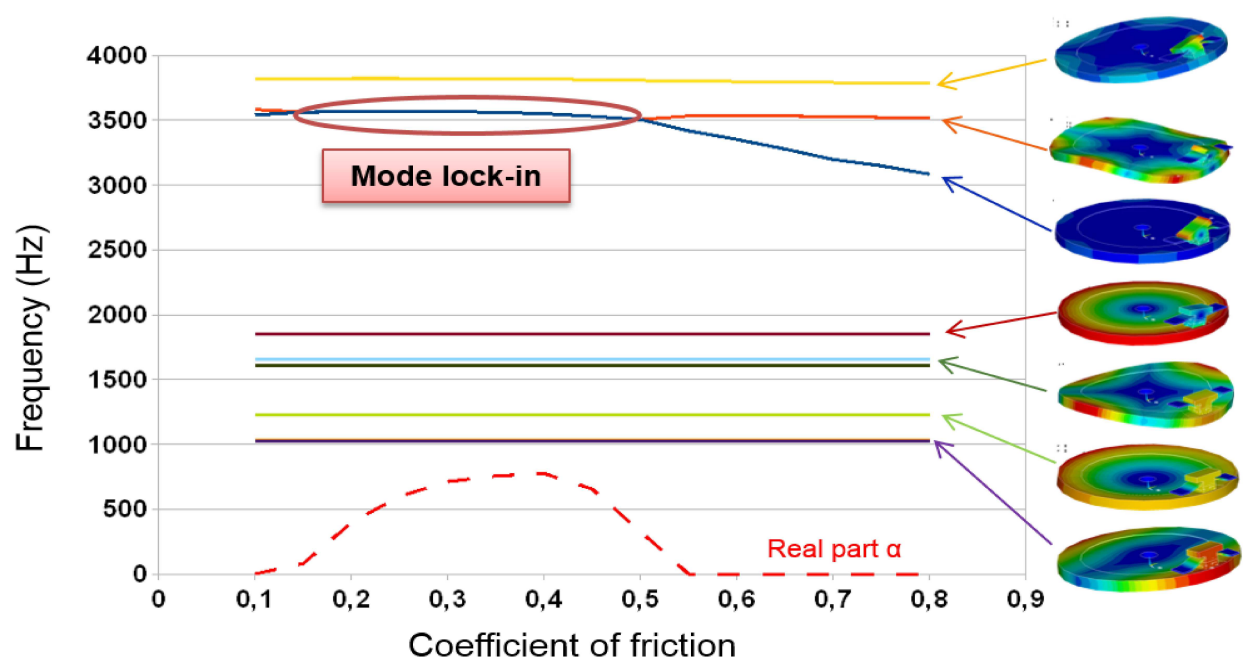

Figure 7: Eigenfrequencies of the pin-on-disc system according to coefficient of friction

According to the results, the eigenfrequencies associated to disc mode are slightly modified. This is due to the high rigidity of the disc relative to stiffness 
variations of the system influenced by the contact conditions. The pad eigenfrequencies are more affected by the evolution of coefficient of friction. This is mainly attributed to the increase in rigidity induced by the increase in contact length [6]. The tilting pad mode (blue curve) and the twisting pad mode (orange curve) coalesce for a friction coefficient between 0.1 and 0.55 , leading to a mode lock-in mechanism and an unstable mode characterized by positive real part (red dashed curve).

\subsection{Results with heterogeneous friction pad material with contact}

In this part, the same problem is solved with an explicit introduction of porosity in the friction pad as previously determined. The mechanical property of matrix is fixed to $3000 \mathrm{MPa}$ for Young modulus and 0.3 for Poisson coefficient although the mechanical properties of the pores are considered to zero for Young modulus, Poisson ratio and density. The results of complex eigenfrequencies with the introduction of pores are illustrated in figure 8 for one set of pores distribution.

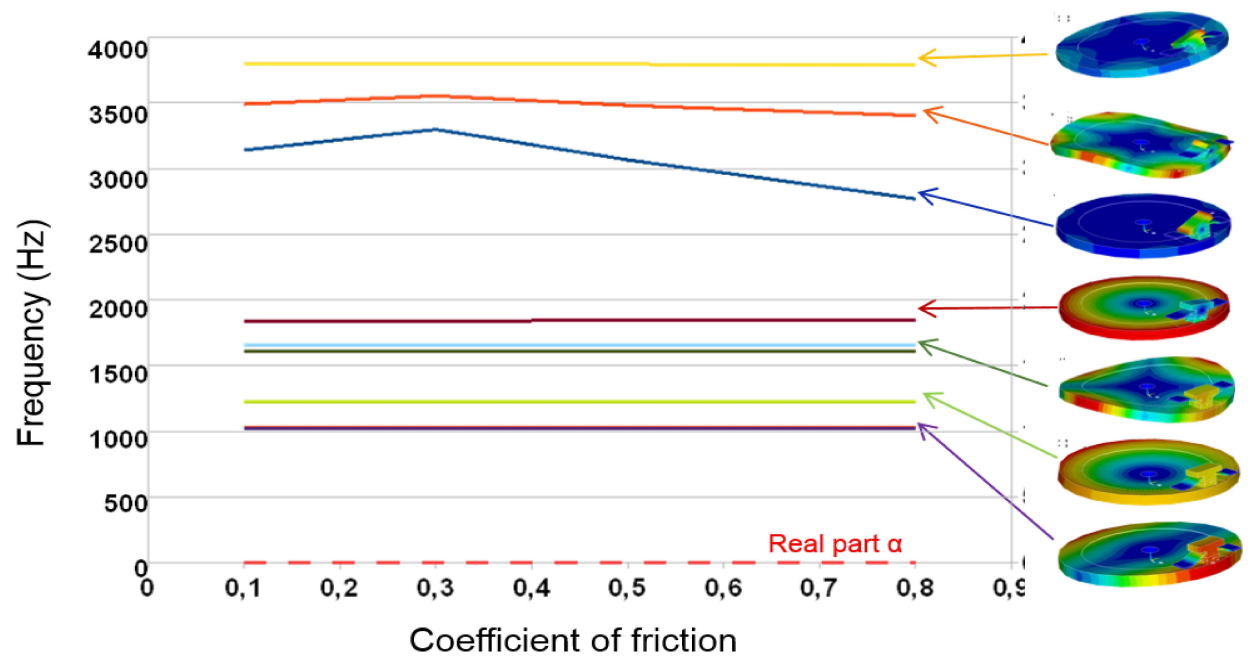

Figure 8: Eigenfrequencies of the pin-on-disc according to coefficient of friction

It can be noted that the eigenfrequencies associated to disc mode are quasi unchanged. But, some eigenfrequencies associated to the pad friction material 
are clearly modified. Indeed, the tilting pad mode (blue curve in figure 8) decreases with a drop of $\sim 600 \mathrm{~Hz}$ while the one associated to twisting pad mode decreases with a drop of $\sim 250 \mathrm{~Hz}$ in comparison to the results obtained with a homogenized friction pad. So, with the introduction of porosity in the system, any mode lock-in appears, illustrated by a real part equal to 0 for all coefficients of friction (red dashed curve).

\subsection{Extension with differents draws of pores distribution}

In this part, the same problem is solved considering a different draw of pores distribution. In this paper, it is not a question of stochastic analysis but this study permits to know if the tendency is global. Here, one hundred random configurations for porosity distribution are treated using the mathematical tool previously described. In figure 9, the range of variation according to one hundred tested configurations for tilting (resp. twisting) mode is plotted in blue (resp. orange).

For all tested configurations, the eigenfrequencies associated to disc mode are quasi-unchanged in contrast of the frequencies associated to pad mode. It can be noted that the eigenfrequencies variation associated to tilting and twisting pad mode are around $250 \mathrm{~Hz}$ according to different configurations. For all configurations, no mode lock-in appears for all tested cases. The probabil-

285 ity distribution of eigenfrequencies are plotted for each coefficient of friction in figure 9 using histograms. Here, the sample mean is equal of $3017 \mathrm{~Hz}$ for the tilting pad mode ( $3349 \mathrm{~Hz}$ for the twisting pad mode) with a standard deviation equal to $66 \mathrm{~Hz}$ (resp. $76 \mathrm{~Hz}$ ). For the worst case (twisting pad mode), the $95 \%$ confidence interval is equal to $[3319 \mathrm{~Hz} ; 3379 \mathrm{~Hz}]$. So, in view of the values of this confidence interval endpoints, the number of random distributions can be sufficient.

This simulation shows that the dynamical behavior of the system is completely affected by the introduction of porosity, even if, as shown, the mechanical properties are quasi-unchanged between homogenized and heterogeneous cases.

295 Therefore the difference of dynamic behavior cannot be explained by this way. 


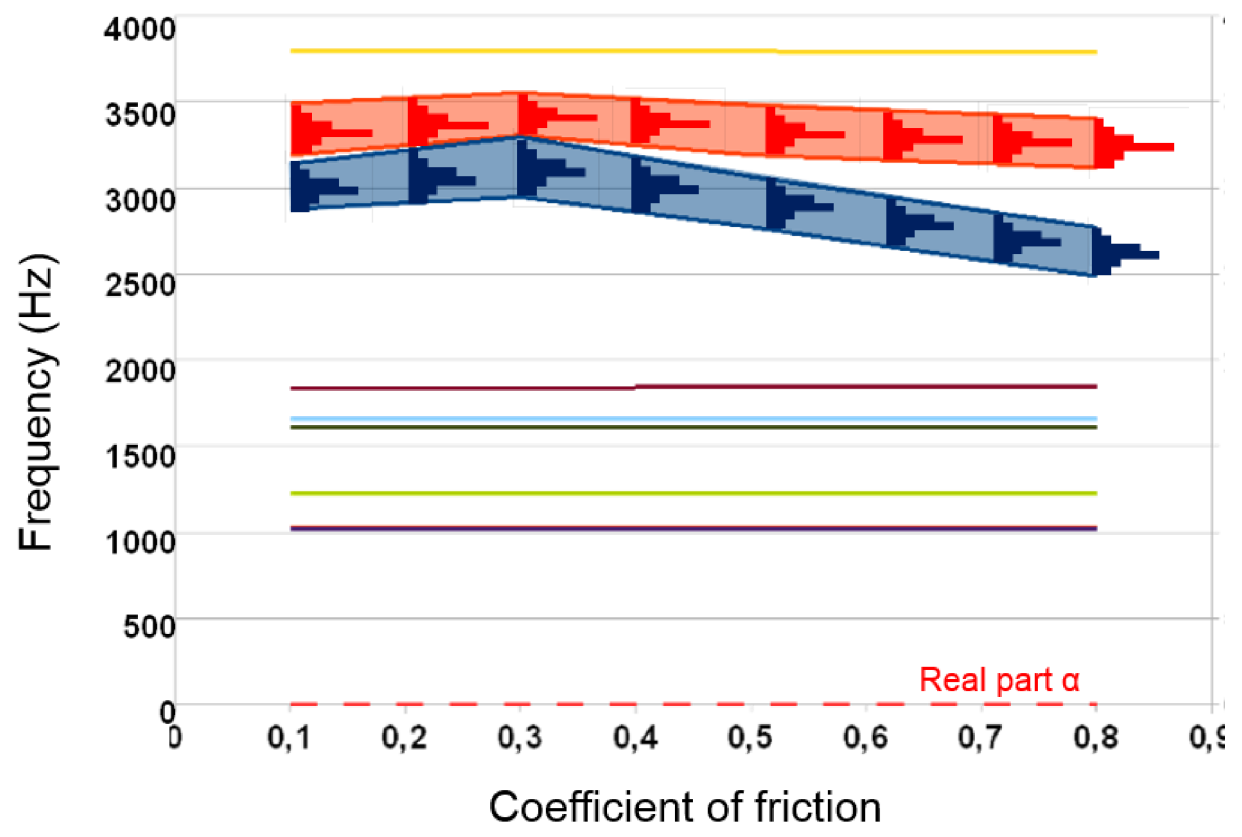

Figure 9: Eigenfrequencies of the pin-on-disc according to coefficient of friction for one hundred random porosity configurations

Another possible way to explain this decrease of eigenfrequencies is the modification of the contact pressure distribution.

\subsection{Interpretation of the results}

In figure $10(\mathrm{a})$, a contact pressure distribution for the homogenized case with a coefficient of friction equal to 0.3 is illustrated. A classic distribution of the contact pressure is due to the friction sliding in the tangential direction and to the static bending deformation of the disc, because of the normal load. Therefore, a more important contact pressure is located at the leading edge, and to the inner contact radius. In figure 10(b), two contact pressure distributions for heterogeneous cases with the same value of coefficient of friction are plotted.

It can be noted that the contact pressure distribution is strongly affected and 


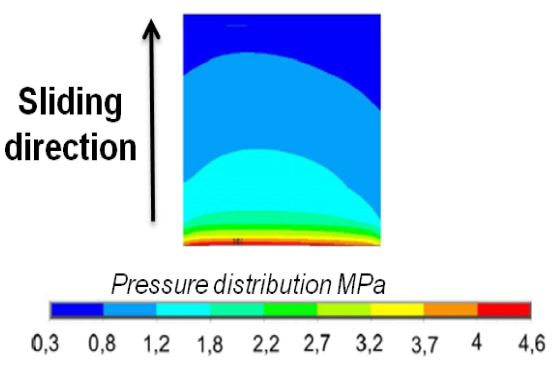

(a)

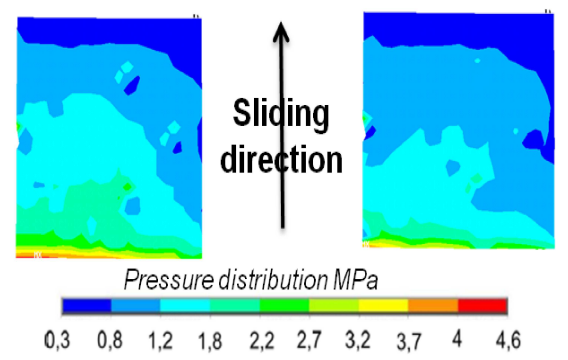

(b)

Figure 10: Contact pressure distribution with a coefficient friction equal to 0.3: (a) Pressure distribution at the pin-contact surface for homogenized material, (b) Pressure distribution at the pin-contact surface for heterogeneous material (2 cases)

can lead to change the dynamic behavior of the system. The contact pressure is logically less continuous in the heterogeneous cases, but also less concentrated at the leading edge. Indeed, the presence of pores, especially the ones near the contact surface, modifies the distribution of the contact pressure. In fact, the local stiffness is equivalent or smaller that found with the homogeneous case which permits regarding to the global system to reduce the rotation of the friction pad in the heterogeneous cases. Moreover, the alteration of the pressure distribution can explain the dispersion of the frequencies in function of the geometric pores raw where systematically the frequencies (associated the tilting and twisting modes) obtained in the heterogeneous cases are smaller than the ones found in the homogeneous case. In function of the geometric pores raw, the rotation of the pad can be more or less important.

Finally, the last results of contact pressure could explain the change of frequencies level. This kind of work can be linked to other such as [26] who shows the effect of groove on squeal by both experimental and numerical methods where the pressure distribution is strongly impacted that can change the frequencies of the problem. 


\section{Conclusions and prospects} heterogeneous friction material with porosity has been developed. The porosity has been firstly identified at the ESRF synchrotron using X-ray tomography. A framework study of morphological generation of pores has been secondly detailed and used to include porosity in a finite element model. Results show clearly that a homogenized case which is mode lock-in, the introduction of heterogeneities leads to mode lock-out even if the homogenized compressive modulus is the same range. The way of explanation is focused on the difference of contact pressure distribution on the pin contact surface which is more evenly distributed for the 335 heterogeneous cases. This can lead to a frequency decrease of the tilting mode involved in the mode lock-in. In prospects, it would be interesting to describe the other components of the formulation to extend the heterogeneous description. For that, it is necessary to use an advanced finite element technique to describe all components. This approach could also be extended to a full brake pad of complete brake disc configuration.

\section{Acknowledgments}

The present research work has been supported by the international Campus on Safety and Intermodality in Transportation, the Nord-Pas-de-Calais Region, the European Community, the Regional Delegation for Research and Technol345 ogy, the Ministry of Higher Education and Research, and the National Center for Scientific Research. The authors gratefully acknowledge the support of these institutions. The investigations and results reported herein are supported by the National Research Agency (France) under the COMATCO research program.

\section{References}

350 [1] Adler, R.J., 2008. Some new random field tools for spatial analysis. Stochastic Environmental Research and Risk Assessment, Vol. 22, pp. 809-822. 
[2] Akay, A., 2002. Acoustics of friction, J. Acoust. Soc. Am., Vol. 111, No. 4.

[3] Alart, P., Lebon, F., 1998. Numerical study of a stratified composite coupling homogenization and frictional contact, Mathematical and Computer Modelling, Vol. 28(4-8), pp. 273-286.

[4] Bonnay, K., Magnier, V., Brunel, JF., Dufrenoy, P., De Saxcé, G., 2015. Influence of geometry imperfections on squeal noise linked to mode lock-in, International Journal of Solids and Structures, Vol. 75-76, pp. 99-108.

[5] Chan, D., Stachowiak, G. W., 2004. Review of automotive brake friction materials. Proceedings of the Institution of Mechanical Engineers, Part D: Journal of Automobile Engineering, vol. 218(9), pp. 953-966.

[6] Duboc, M., Magnier, V., Brunel, J.F., Dufrénoy P., Rejdych, G., Chancelier T., 2010. Influence of contact conditions and pad geometry on disc brake squeal noise, 6th European Conference on Braking JEF 2010, Lille, France, pp. 247-25.

[7] Heussaff, A., Dubar, L., Tison, T., Watremez, M., Nunes, R.F., 2012. A methodology for the modelling of the variability of brake lining surfaces. Wear, Vol. 289, pp. 145159.

[8] Hoffmann, N., Fischer,M. , Allgaier, R., Gaul, L., 2002. A minimal model for studying properties of the mode-coupling type instability in friction induced oscillations, Mechanics Reasearch Communications, Vol. 29, pp. 197205.

[Homtools] Homtools.http://homtools.lma.cnrs-mrs.fr.

[10] Kimura, Y., Hatori, K., 2013. Visualization of the Pores of the Brake Lining, Eurobrake2013.

[11] Kinkaid, N., O'Reilly, O., Papadopoulos, P., 2003. Automotive disc brake squeal, Journal of Sound and Vibration, 267, p.105-166. 
[12] Liu, P., Zheng, H., Cai, C., Wang, Y.Y., Lu, C., Ang, K.H., Liu, G.R., 2007. Analysis of disc brake squeal using the complex eigenvalue method, Applied Acoustics, Vol. 68, Issue 6, Pages 603-615.

[13] Massi, F., Baillet, L., Giannini, O., Sestieri A, 2007 Brake squeal: Linear and nonlinear numerical approaches, Mechanical Systems and Signal Processing, Vol. 21(6), pp. 2374-2393.

[14] Mbodj, C., Renouf, M., Baillet, L., Berthier, Y., 2010. Modeling of Carbon/Carbon Composites under tribological Solicitations, Proceedings of the STLE/ASME International Joint Tribology

[15] North, M.R., 1972. Disc brake squeal - a theoretical model, Technical Report 1972/5, Motor Industry Research Association, Warwickshire, England.

[16] Oden, J.T., Martins, J.A.C., 1985. Models and computational methods for dynamic friction phenomena, Computer Methods in Applied mechanics and Engineering, 52, p.527-634.

[17] Ouyang, H., Nack, W., Yuan, Y., Chen, F., 2005. Numerical analysis of automotive disc brake squeal: a review, International Journal of Vehicle Noise and Vibration, 1, p.207-231.

[18] Pernin, J.N., Dubois, C., Rouge, N., 1997. A model of heat transfer in brake pads by mathematical homogenisation. Science and Engineering of Composite Materials, Vol. 6(4), pp. 219-224.

[19] Roubin E., 2013. Modélisation numérique multi-échelles des matériaux cimentaires : apport des modèles morphologiques, $\mathrm{PhD}$ Thesis.

${ }_{400}$ [20] Rouge, N., Dubois, C., Vermillet, C., 2011. Characterization of the Open Porosity of Brake Pads. II. Correlations Between Volume Porosity and Surface Area Porosity. Structural Modeling, Science and Engineering of Composite Materials, vol. 4(4), pp. 215-222. 
[21] Rouquerol, J., Avnir, D., Fairbridge, C.W., Everett, D.H., Haynes, J.H., Pernicone, N., Ramsay, J.D.F. Sing, K.S.W., Unger, K.K., 1994. Recommendations for the characterization of porous solids, International Union of Pure and Applied Chemistry, Vol. 66(8), pp. 1739-1758.

[22] Schneider, C.A., Rasband, W.S., Eliceiri, K.W., 2012. NIH Image to ImageJ: 25 years of image analysis, Vol. 9, pp. 671-675.

[23] Spurr, R.T., 1961. A theory of brake squeal, Proc.Inst. Mech. Eng. 1, p.3352.

[24] Temizer, I., Wriggers, P., 2008. A multiscale contact homogenization technique for the modeling of third bodies in the contact interface, Computer Methods in Applied Mechanics and Engineering, Vol. 198(3-4), pp. 377-396.

${ }_{415}$ [25] Trichês, M.J., Gerges, S., Jordan, R., 2008. Analysis of brake squeal noise using the finite element method: A parametric study, Applied Acoustics, Vol. 69(2), pp. 147-162.

[26] Wang, D.W., Mo, J.L., Ouyang, H., Chen, G.X., Zhu, M.H., Zhou, Z.R., 2014. Experimental and numerical studies of friction-induced vibration and noise and the effects of groove-textured surfaces, Mechanical Systems and Signal Processing, 46, p.191-208 